\title{
The ecology of natural capital accounting
}

\author{
Paper prepared for The Oxford Review of Economic Policy
}

Final version 22/8/18

\author{
Georgina M. Mace \\ Centre for Biodiversity and Environment Research, \\ Department of Genetics, Evolution and Environment. \\ University College London \\ Gower Street \\ London WC1E 6BT
}

\section{Introduction}

In common with the other capitals natural capital is valued because of the goods and services it provides (Barbier, this volume). But natural capital is different to human and especially to produced capital in several important respects. It exists and does not have to be createdand its functions are malleable and adaptable. If it is treated well it will continue to produce and provide goods and benefits at no cost potentially for ever, but if treated badly or overused it can collapse, often suddenly, and be difficult, expensive or impossible to recover. The growing recognition of the importance of natural capital for society and the economy has led to an increased interest in natural capital accounting. This should not be simply a means to place a monetary value on the natural environment in order that it is taken more seriously in decision-making. Rather, accounting should be the means by which governments, corporations and individuals can take proper responsibility for the essential components of natural capital that underpin society and a good life (the assets), record the condition of these assets and how this is changing over time, and ensure that provision is made when they fall below critical levels (see Helm, Barker, Mayer, this volume). In order for the accounting to be responsible and effective it will be necessary to consider the natural science that lies behind these critical components and use this to develop relevant and informative metrics. So far, despite the burgeoning set of tools and metrics relating to natural capital accounting and the green economy, hardly any attention has been directed towards these fundamental considerations that lie at the heart of accounting on the one hand and environmental science on the other. Relevant metrics should inform decisions about what assets go into the accounts, what measures are used to record their condition over what scales of space and time, and how to determine assets at risk and the way in which liabilities and maintenance costs should be determined.

Here I review natural capital from the perspective of ecological science in order to emphasise features that should not be overlooked in accounting and valuation. This is with a view to improving the basis 
for natural capital accounting as well as for stimulating the necessary research at the interface of ecology and accounting.

\section{Defining and delimiting natural capital}

There are potentially many ways to measure the condition and quantity of the natural environment, and more indicators and metrics are being developed all the time. But in order that natural capital accounts meet their purpose and provide relevant information about the key assets and their condition, careful thought is needed about what components to include and how to measure their condition. Many metrics of natural capital simply aggregate certain easy-to-gather natural environment indicators and link these to estimates of the monetary value of associated ecosystem services. In doing so they provide somewhat biased and incomplete estimates of value, but there is also a risk that they overlook entirely the most critical components of natural capital, the very assets that responsible accounting should be prioritising and therefore to consider what natural capital is and how it provides value both now and in the future.

The accepted definition of capital is that it is a stock of assets that supports a flow of benefits to society. There are fundamentally three kinds of capital, (i) produced or manufactured capital (roads, buildings, machines) (ii) human capital (health, knowledge, culture and institutions), and (iii) natural capital (the resources and functions of the natural environment). Natural capital includes living and non-living natural resources in air, water, land and below-ground, so according to this definition it is broader than ecosystems and includes minerals, fossil fuels, air and water. Crucially, it also includes the interactions and processes that are involved in nature's own capacity to persist, based on physical, biological and chemical processes (e.g. weathering, the water cycle, evolution, nutrient cycling, recruitment and ecological interactions). All human welfare ultimately depends upon the use of these three kinds of capital but natural capital alone is available without human intervention of any kind, although for it to contribute to welfare and production there is almost always the need for some input of human or produced capital (Barbier 2013). The UK Government's Natural Capital Committee (NCC) defined natural capital as follows, "Natural capital refers to the elements of nature that produce value or benefits to people (directly and indirectly), such as the stock of forests, rivers, land, minerals and oceans, as well as the natural processes and functions that underpin their operation" (Natural Capital Committee 2013).

Natural capital therefore includes all elements of the environment, including natural resources, which provide benefits to people now and in future (as well as elements that with management might produce fewer dis-benefits). But some natural capital components are not subject to anthropogenic influence (whether intended or not), and so are excluded from a record of natural capital on pragmatic grounds. Natural capital is therefore not everything in the natural environment. It will only include elements that have some actual or potential relevance to human welfare, now or in the future; 
elements that are changing or likely to change in measurable levels over policy-relevant timescales (years to many decades); and that are plausibly subject to management by people in some way to restore or recover, or to restrict use to non-significant rates of loss, or for use by future generations. These criteria lead to the exclusion of certain natural capital components such as the sun, mountains or clouds, but still includes just about everything that is visible and manageable in the natural world (Natural Capital Committee 2014, 2013).

Many natural capital assessments treat ecosystem services as equivalent to natural capital for both reporting and valuation purposes. This is understandable given that the main way that the value of natural capital is understood is through the provision of goods and services. However it can be a serious error to confuse the stock (capital) with the flow (of goods and services). This could easily lead to investments in maintaining flows of certain highly-valued goods and services while the stock (system) on which the flow depends is left to deteriorate. The NCC recognises natural capital as a series of overlapping assets that are formed and maintained by natural processes (e.g. species, ecological communities, soils, water, and forests). These natural assets are managed by people to provide a set of goods and service from which society benefits (e.g. food, hazard regulation, recreation) (Natural Capital Committee 2014). Most of these goods and benefits depend on combinations of multiple natural assets, of which most contribute in some way to just about all kinds of benefits. Hence there is no simple or linear relationship between assets and benefits yet this is what is required to justify an approach to valuing the assets on the basis of the flow of goods and services. The risks of treating flows as proxies for the condition of stocks are increased when not only are the relationships between stocks and flows are neither simple nor linear but also when, as is commonly observed, there are poorly understood thresholds in the relationship between assets and benefits (Mace et al. 2015).

Are ecosystem services the contributions from ecosystems to production or the benefits to society from ecosystems? This confusion has persisted since the Millennium Ecosystem Assessment (2005) defined ecosystem services as the benefits that people derive from nature. A problem with this definition is that many of these benefits lie several steps away from functions and processes of the natural environment and they involve multiple interacting processes in nature as well as inputs of produced material and human labour and resources. This makes both attribution and valuation problematic (Fisher and Turner 2008). However, distinguishing ecosystem services as those that directly underpin benefits to people and explicitly separating ecosystem services from ecosystem functions and processes, makes the measurement of ecosystem service values both plausible and legitimate by recognising the final services and avoiding double counting (Bateman et al. 2011, Fisher et al. 2008, Balmford et al. 2011, Fisher and Turner 2008). Treating ecosystem services as the contribution from ecosystems to production also allows ecosystem accounting to be linked to ecosystem services (Edens and Hein 2013) and it is then possible to define ecosystems' capacity and 
capability in terms of the actual or potential supply of ecosystem services, even recognising that there may be multiple ecosystem services from the same ecosystem unit (Hein et al. 2016)

Sorting out the valuation of ecosystem services in this way allows for economic analyses of decisions about land use to be compared using economic tools (Bateman et al. 2013), and even to evaluate the potential benefits of investing in different ecosystem types. For example, the Natural Capital Committee (2015)showed that national scale investments in woodlands or wetlands could deliver return on investments at Benefit:Cost ratios of up to 8:1, comparing favourably with built infrastructure investments such as road and railway schemes. Such valuations are useful for decisionmaking, in particular they could significantly influence investors into natural capital stocks and decisions about major infrastructure projects. It is worth noting though that such estimates, based on Net Present Values, will inevitably focus most strongly on services and benefits that are currently of interest and highly valued, and they miss the elements that are difficult to value in monetary terms. For example, current ecosystem valuations nearly always include carbon sequestration and storage alongside market estimates for produced goods such as timber and crops. Even a few decades ago carbon values would have been unlikely to feature significantly and the focus might have been more firmly on tourism and recreation. In future the contribution of the landscape to mitigating risks from extreme weather such as floods, storms and heatwaves is likely to feature more significantly. These ecosystem accounts therefore remain partial and biased estimates of the potential contributions of any ecosystem to society and inevitably prioritise currently known needs over future options.

Valuing the stock via the sum of its benefits or values suffers from another difficulty. It treats the natural capital stock as if it is a simple production system whereby input of some kind leads to predictable changes in the output and hence the flow of benefits to society. In reality the stock is not a simple input-output device but is a complex system. It is difficult, or even impossible, to predict the consequences of simple interventions in ecosystems, and especially to extrapolate across scales and sectors (DeFries and Nagendra 2017). The complex system is characterised by feedback loops, nonlinearities and alternative states, which mean that apparently straightforward interventions nearly always have unintended consequences. However recent insights from complexity theory suggests that embracing the complexity and working with it will not only limit unforeseen consequences but may also suggest useful new approaches (DeFries and Nagendra 2017), In general, modest enhancements to existing systems are likely to present lower risks than radical shifts. These risks of unintended consequences might also provide a justification for maintaining the current (or very recent) state of natural capital assets on the grounds that interventions will generally lead to deterioration, although on this basis many useful interventions (such as high yield agriculture) might also be ruled out.

Biodiversity values are especially highly contested. Biodiversity means the variety of life but it is a complex concept and can be measured in many different ways using a variety of metrics (for example at the level of genes, species, ecosystems, and counting either or both of diversity and abundance). 
Many economic assessments miss biodiversity completely and for obvious reasons focus instead on the utilitarian goods and services. But biodiversity should not be ignored. The diversity and functioning of life on Earth is the defining feature of our planet. And the defining feature of living systems is their ability to adapt and evolve through the presence of genetic variation and the process of natural selection. Biodiversity is valued by people in many different ways, including the richness and beauty of wild species. But biodiversity also plays a variety of critical roles in underpinning ecosystem processes, functions and services, and so biodiversity loss is not simply the decline of a cultural service, but can also threaten key ecosystem services that are enhanced or insured by some kind of biodiversity (Cardinale et al. 2012, Mace, Norris, and Fitter 2012). In principle therefore biodiversity needs to be considered as a component of natural capital but also as a benefit in its own right (Oliver et al. 2015) although the components and metrics for biodiversity will vary (Mace, Norris, and Fitter 2012, Mace et al. 2015).

There are also a series of moral arguments against the valuation of biodiversity (e.g. Silvertown 2015) and concern that the process of valuation itself diminishes the 'intrinsic' value of nature. The intrinsic value of biodiversity is commonly discussed but what exactly is meant by this and how intrinsic value can or should contribute to decision-making is very unclear. These arguments have significance, especially considering that species are effectively irreplaceable and many natural features hold symbolic and spiritual values. However the debates around intrinsic versus instrumental values have generally been unproductive, and so conservationists probably need to move beyond these general statements and develop more explicit arguments about what it is that they value in the natural world and what needs to be done in order to protect these valued elements (Batavia \& Nelson 2017). Such arguments should consider both costs and values of actions and inactions. They do not need to be based on monetary valuation but can embrace many different kinds of values and levels of biological organisation (Pearson 2016). Given that it seems to be the monetisation process that lies at the heart of many concerns over natural capital assessments of biodiversity it is relevant to point tomany existing biodiversity policies at local, national and international level that include targets for biodiversity conservation derived through consultative and democratic processes, that can legitimately be considered to be a societally based statement about what good biodiversity conservation would achieve. Thesedo not include any monetisation yet remain legitimate expressions of societal values. A final consideration for natural capital concerns the degree to which it is replaceable by other kinds of capital. This is the weak versus strong sustainability debate (see other papers in this issue, Barbier). Critical natural capital has been defined as the essential physical subset of natural capital that must be preserved, because it cannot be substituted for by any form of manmade capital (De Groot et al. 2003). There are many debates about critical natural capital and emerging evidence that many ecosystem services can be replaced with technological innovations (Bullock et al. 2011, De Groot et al. 2013). What seems harder to replace is biodiversity itself and certain core ecosystem and 
ecological processes. Many natural capital functions can be provided through engineered solutions or behavioural change. For example, the water regulating properties of flood plains can be replaced with dams or barrages; the natural processes of water purification can be replaced with chemical and physical processing, and even the aesthetic pleasures of seeing wildlife can be replaced (to some disputed degree) with high quality film, or immersive museum and zoo experiences. But so far we have no means to replace species or reverse extinctions, or to replicate people's experiences of the natural world. The re-establishment of intact ecosystem types such as tropical forests of coral reefs is expensive and time-consuming and may not actually achieve the same levels of function as the original ecosystem, and there has been slow progress in engineering alternative to natural energy production (via photosynthesis) or replacing the core functions of the Earth system such as nutrient and water cycling. Hence, at this stage then it is useful to consider the relevant environmental science, and to understand what it is that nature does really for people.

\section{Functions of the natural environment}

The natural environment exists and its fundamental functions have arisen and evolved over the course of billions of years. The living components of nature exploit these fundamental functions and processes and they have evolved and become adapted to changes in conditions, including those brought about by the biota itself. In the past several thousand years, the human population has massively increased in number and become a major force driving change in the Earth's systems. In the past 150 years or so, these changes have become more profound as the size and impact of the human population has increased exponentially.People now dominate the Earth and drive many of its functions. There are few areas of the Earth that are not impacted by people in some way and s the extent to which intact 'nature' still exists in a form that is unaffected by people is debateable. Recognising these recent impacts some researchers have highlighted nine Earth system boundaries that need to be respected if the ability of human civilisations to prosper is not to be put at risk through pushing Earth's systems beyond a safe operating space (Rockstrom et al. 2009, Steffen et al. 2015).

The natural environment provides a range of fundamental functions, but at the core lie processes such as primary production (biomass from photosynthesis), Earth's systems that cycle essential nutrients (such as Carbon, Nitrogen and Phosphorous), the water cycle, the climate system, the provision of land surface and the natural systems that control pollution and other hazards. These core processes underpin the planetary boundaries (Steffen et al. 2015), and they lie at the heart of the environmental contributions to people (Figure 1). In order to secure and sustain essential functions and services, human activity intervenes in these core processes. For example people intervene to change the environment to grow more food than would be otherwise available, to divert and control rives and waterways, to domesticate wild species for crops, livestock or pets, and to radically alter the land surface to provide habitation, transport and industry. Figure 1 depicts the core natural processes are 
adapted and supplemented by human activity to secure ecosystem services and ultimately to underpin resilient and thriving societies. Nature does not do everything, but it does underpin almost everything on which society depends, making its contribution both extensive and fundamental, and hence difficult to measure.

Figure 1

\section{Human society}

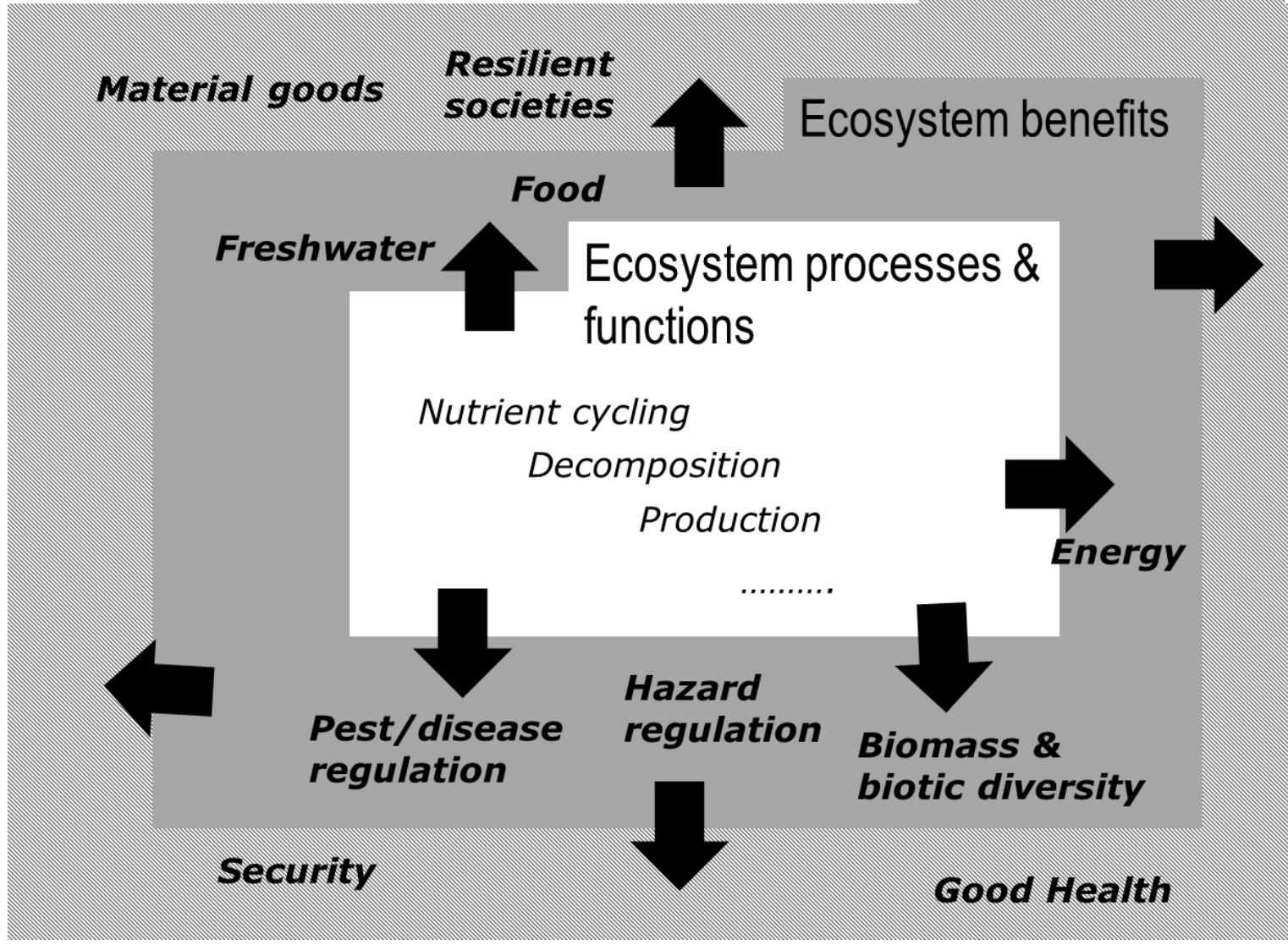

The Millennium Ecosystem Assessment recognised four categories of ecosystem services (Supporting, Provisioning, Regulating and Cultural). A recent consensus is that Supporting services are fundamental ecosystem processes and so should not be classified as services since they underpin everything else (Carpenter et al. 2009). There are many debates about cultural services as well as about the generality of any classification of ecosystem services. Without doubt the human-nature relationship is complex and we should not be surprised that there are so many ways to try to represent it (Mace 2014).

Whatever the classification is, there are clearly many measurable benefits that people derive from nature, and these are what should characterise the natural assets in a natural capital framing. As discussed above, identifying the links from ecosystem processes and functions to ecosystem services and benefits is very complex, and while some biodiversity components or ecosystem processes are clearly fundamental to certain benefits it is harder to prioritise them. Thus, genetic diversity and 
population abundance are crucial for biodiversity conservation; soil, water, nutrients and crop plants are necessary for agricultural production, and so on. But we could never assert that genetic diversity did not matter at all for most benefits or that soil, water and nutrients are dispensable or replaceable. In principle a careful analysis of interlinkages between fundamental processes and benefits would allow the definition of critical natural assets that should form the basis for accounting.

In practice this is more complicated than it might appear. First, the asset-benefit relationships are complicated, multi-dimensional, multi-scale and non-linear. Hence any attempt to map assets to services rapidly becomes enormously complicated. Second, ecosystem services are usually analysed one at a time, yet there are always interactions between different services that are missed in simple stock-flow accounting for individual services. This is a key problem for simple ecosystem accounting, potentially addressed by considering bundles of services (Raudsepp-Hearne, Peterson, and Bennett 2010), by defining ecosystem capacity (Hein et al. 2016) or by identifying only the critical asset for any particular benefit (Mace et al. 2015). All of these approaches have drawbacks and reveal the fundamental disconnection between valuing individual services and the potential for ecosystem shifts that are poorly understood.

Rather than seeing multifunctionality as a confounding factor, it may be better to recognise it as a desirable asset of ecosystems, and one that is hard to replace or replicate in the engineered alternatives. Dams and barrages for example do little more than to control flood water, whereas natural flood plains provide multiple benefits alongside flood control including agriculture, recreation, wildlife conservation etc. Therefore the return on investment in a flood plain may well exceed that of a barrage even if it is less efficient at flood control. New approaches to measuring ecosystem multifunctionality emphasise that the value depends on who the stakeholders are, who is demanding or using which service and how this interacts with other services. Hence the multidimensional value of a landscape depends on the stakeholders involved and there are methods available to measure these values (Manning et al. 2018).Ecosystems are continually exposed to many kinds of pressures, including local perturbations (e.g. a pollution event), regional catastrophes (e.g. a novel pathogen) and progressive large-scale shifts in conditions (e.g. land use change, climate change). While many engineered systems may be designed to withstand these pressures, there are costs to building in resilience that may trade-off with efficiency. In contrast natural systems have their own coping and adapting mechanisms that will allow for ecosystem functions to be resilient, at least to a degree, in the face of many different kinds of pressures. Oliver et al. (2015) for example describe properties of species, ecological communities and landscapes that enhance the resilience of ecosystem functioning (Table 1). Along with non-linearity and multifunctionality, resilience can be a desirable property of natural capital that is valued in its own right (Oliver et al. 2015).

Table 1. Ecological mechanisms underpinning resistance $\&$ recovery of ecosystem functions to perturbation, redrawn from Oliver et al., 2015 


\begin{tabular}{|l|l|l|}
\hline Species & Ecological Community & Landscape \\
\hline Sensitivity to change & $\begin{array}{l}\text { Correlations between responses to } \\
\text { environmental change and their effects }\end{array}$ & $\begin{array}{l}\text { Local environmental } \\
\text { heterogeneity }\end{array}$ \\
\hline Population growth rate & Functional redundancy & Functional connectivity \\
\hline Adaptive plasticity & Network interaction structure & $\begin{array}{l}\text { Potential for alternate } \\
\text { stable states }\end{array}$ \\
\hline Genetic diversity & & Area of natural habitat \\
\hline $\begin{array}{l}\text { Density dependent } \\
\text { responses }\end{array}$ & & \\
\hline
\end{tabular}

\section{Measuring and recording changes to natural capital}

This overview of natural capital from the perspective of ecology allows for a critical review of the various approaches to natural capital accounting and valuation. There are essentially four different approaches that may be taken; each of which uses a different starting point, (1) Ecosystem-service based which uses value of the flows of goods and services; (2) Ecosystem-type based using some accepted classification of ecosystems and account for ecosystem services and capacity; (3) Outcomebased using political and deliberative processes to determine the desired outcomes from the natural environment and record progress in achieving these, and (4) Ecosystem-capability as an approach to account for the fundamental and irreplaceable properties of natural capital using a capabilities approach. These four are not mutually exclusive but they do entail very different starting points, datasets and methods, and each has certain advantages and disadvantages.

As discussed above, an approach based on Ecosystem-services uses aggregate values of natural capital derived from the total economic values of ecosystem services. It builds on the growing information base that classifies ecosystem types according to the services they provide and links this with estimate of the social value (Bateman et al 2011) or the inclusive value of the benefits(Arrow et al. 2012). Advantages of this approach are that it is practical and achievable in a growing number of local and regional situations, and that the necessary data is ever more available through remote-sensing and integrated online databases. In addition this method provides quantitative results that can be useful and influential with decision-makers using either physical (Nelson et al. 2009, Ouyang et al. 2016) or monetary values(Bateman et al. 2013). The disadvantage of this approach is that it inevitably favours currently significant services and those that are easy to measure and value. This approach also implicitly measures the flows and not the stocks, there is a risk that it greatly undervalues natural capital, and that some significant future services that are not well known or understood today could be missed altogether (Mayer, this volume). 
A second commonly-used approach is the use ecosystem-types to start the account using a classification of ecosystems that may or not be spatially mapped onto the landscape, and then use some kind of look-up table to record the ecosystem service delivery expected from each ecosystem type. This is broadly the approach being adopted by the UN SNA and SEEA CF. It implicitly uses ecosystem types as natural capital assets. This has some drawbacks especially in the absence of any agreed functional classification of ecosystems that works across scales and contexts. It easily misses the important factors to do with who the stakeholders are - ecosystem services are defined in terms of their benefits to people and this approach assumes a homogeneous demand side. It also misses multifunctionality and resilience aspects. However, it is an easy-to-use approach that can integrate easily with other land-based accounting systems ( (Edens and Hein 2013). Hein et al. (2016) make the case that a more complete understanding of ecosystem assets requires consideration of the concepts of capacity, capability and potential supply, in addition to indicators of ecosystem extent, condition and the net present value of the expected flow of ecosystem services.

A third, rather different approach is the one taken by the UK Government in their recent 25 Year Environment Plan (25YEP) which is essentially an outcome-based approach. This plan is presented as a natural capital plan with an overarching ambition to improve the state of the natural environment within a generation (Defra 2018). However, the substance of the 25YEP is not framed in this way. Instead it is centred on achieving 10 goals concerning the state of the natural environment and the pressures that are placed on it by 2043. The goals are summarised in Table 2. The first 6 goals describe the features of an improved environment; these can be called 'outcome goals' because they specify an end state for the environment that the plan should achieve. The final four goals are directed towards reducing particularly significant pressures (climate change, waste, polluting chemicals and biosecurity); these require the impacts on natural capital to be reduced. This could be interpreted as defining the state of nature that meets society's needs and therefore the state of natural capital that should be achieved and maintained.

\section{Table 2. Summary of Goals from the 25 Year Environment Plan}

1. Clean air

2. Clean and plentiful water

3. Thriving plants and wildlife

4. Reducing the risks of harm from environmental hazards

5. Using resources from nature more sustainably and efficiently

6. Enhancing beauty, heritage and engagement with the natural environment

7. Mitigating and adapting to climate change

8. Minimising waste

9. Managing exposure to chemicals

10. Enhancing biosecurity 
This approach avoids the problems with partial or biased valuation of ecosystem services and is able to represent bold outcomes for the environment. Properly followed through using a careful appraisal of projects that could achieve the goals, this plan could prescribe a set of natural capital investments needed to restore natural capital to the state and condition that society requires it to be in. It would without question be improved relative to the current situation. There are some potential pitfalls in this approach though, especially if the goals lack quantitative targets, if the appraisal process is too narrowly focussed on one goal at a time and a set business-as-usual interventions, or if there is no process to embed the outcomes into national accounting. In practice, all of these risks are real and already playing out.

The fourth and final option follows from many of the points made earlier in this paper about the ecological underpinning for natural capital assets and is based on a concept of critical ecosystem capability. In principle the metrics for natural capital should reflect its most critical and irreplaceable components and processes. These are the elements of natural capital that cannot be replaced by technology or some alternative human intervention, and they are the features that once lost are the most difficult to recover. So what are the assets and how should the condition of an asset be measured? In principle the measure should reflect the extent to which different natural assets preserve their defining features of form and function. There will be different metrics for different categories of natural asset (forests versus salt marsh for example). How should the metrics be chosen and on what basis should the baseline be selected?

One option is to use recent historical state as the "desired" state against which the current condition is measured, and use this to estimate the restoration/recovery cost and maintenance cost. A concern here is that this recent or historical state and the metrics used to monitor the asset may fall far short of what is actually possible, wanted or needed. For example, there is no basis on which to claim that the current coverage or configuration of forest/woodland in England is in any way what we would want to advocate as a baseline or target. In fact there is good evidence that for woodland and for other ecosystem types (moorland, salt marsh, wetland) that relatively small investments in more coverage and better quality areas would have many benefits and very good BCA values(Natural Capital Committee 2015).

A logical and consistent approach would be to consider instead the core ecosystem functions described above. This would be in place of actual services and benefits and would use an approach analogous to the capabilities approach for measuring human wellbeing/welfare(Sen 2010). Many economists prefer to use the capabilities approach for human development - measures that consider not what people have or are, but what they could achieve. In this way it is the functioning and capabilities of society that are what are to be secured, not some measures of people's state/condition. The capabilities approach emphasises both personal choices and contextual variation. It comes from answering the question, "what is the nature of the life we have reason to value"? In the case of the 
natural environment, we could analogously ask, "“"what is the nature of the natural environment we have reason to value"? This would define the capabilities and functioning required from the natural environment for society. It would move the measures away from the more immediate and mechanistic functions (air quality, flood risk) and towards the fundamental and irreplaceable processes and components. It would instead emphasise core natural features (self-sustaining populations; connectivity; genetic diversity; adaptation and resilience, primary production, nutrient cycling, etc.). These functionings and capabilities have already been extensively considered in the environmental sciences. They partly map onto the 'supporting services' of ecosystems, the underpinning processes on which all ecosystem services depend. Natural asset condition would then be measured in terms of its potential to support these functions on a continuing basis without interventions. We know already that these are the functions that are hardest or impossible to replace with technology/produced capital (Fitter 2013). Following this approach the metrics for assets should be based on the fundamental features of natural systems - their functions and processes. There are several existing, relatively straightforward classifications of such features. For example, Balmford et al. (2011) describe the core ecosystem processes that underpin all ecosystem functions and services. They list primary production, decomposition, nutrient cycling, water cycling, weathering/erosion, ecological interactions, evolutionary processes.

The advantage of this approach is that it is recording the right things - the critical functions and services consistent with accounting principles and environmental science. A difficulty is that this is novel and potentially quite difficult to implement, and it may be more complicated to link to other existing accounting systems. Although there are metrics for all the above functions, and despite the fact that there is extensive data already available on most of them, the task to organise and streamline the metrics would be fairly substantial.

\section{Recommendations on information for accounting:}

This paper has reviewed the ecological science underpinning of natural capital. It leads to several conclusions for new work and for better practice in natural capital accounting. Ideally the metrics would result from a science-informed understanding of what is and is not replaceable, what and where are the changes that are particularly difficult or even impossible to reverse, and over what scales of space and time can these changes best be represented.

In the first place there are many reasons to be very wary of both monetary valuations and ecosystem service accounts if the purpose is to undertake natural capital accounting. Gaps and biases in valuation, and a focus on flows not stocks will potentially provide a serious underestimate of the importance of natural capital and a focus on the wrong assets. In fact, as the NCC has shown it is 
possible to assess natural assets at risk, and make plausible recommendations for investment using a risk register based entirely on existing evidence about asset-benefit relationships and existing thresholds for key benefits (Mace et al. 2015; NCC 2015).

Second, the most important outcome of natural capital accounting will be to identify priorities for investment. Using the comprehensive approach developed by the NCC (2015) which evaluated all potential benefits from particular assets (in this case habitat types), it was possible to use CBA appraisal to compare large capital investments in natural infrastructure and the evidence suggested that natural systems could compete favourably with built infrastructure (roads, railways) in terms of the return on investment. This result would have been missed if the set of services evaluated had been selective, or if the benefits that are hard to evaluate had been excluded.

Third, the key features of natural systems that need to be taken seriously into account in natural capital accounting are to do with the complex system properties of the natural environment. The nonlinearities in benefit-asset relationships, the irreversibilitys, multifunctionality, adaptability and resilience are key features of natural systems that need to be taken into account. One ways to do this is to base accounting around the core features of ecosystems and ensure that these fundamental functionings and capabilities are maintained for future generations and not squandered in present-day endeavours to maximise a small set of currently highly valued services.

\section{REFERENCES}

Arrow, Kenneth J., Partha Dasgupta, Lawrence H. Goulder, Kevin J. Mumford, and Kirsten Oleson. 2012. "Sustainability and the measurement of wealth." Environment and Development Economics no. 17:317-353. doi: 10.1017/s1355770x12000137.

Balmford, Andrew, Brendan Fisher, Rhys E Green, Robin Naidoo, Bernardo Strassburg, R Kerry Turner, and Ana SL Rodrigues. 2011. "Bringing ecosystem services into the real world: an operational framework for assessing the economic consequences of losing wild nature." Environmental and Resource Economics no. 48 (2):161-175.

Barbier, E. 2013. "Natural Capital." In Nature in the balance, edited by D Helm and C. Hepburn. Oxford: Oxford Univeristy Press.

Bateman, Ian J., Amii R. Harwood, Georgina M. Mace, Robert T. Watson, David J. Abson, Barnaby Andrews, Amy Binner, Andrew Crowe, Brett H. Day, Steve Dugdale, Carlo Fezzi, Jo Foden, David Hadley, Roy Haines-Young, Mark Hulme, Andreas Kontoleon, Andrew A. Lovett, Paul Munday, Unai Pascual, James Paterson, Grischa Perino, Antara Sen, Gavin Siriwardena, Daan van Soest, and Mette Termansen. 2013. "Bringing Ecosystem Services into Economic Decision-Making: Land Use in the United Kingdom." Science no. 341 (6141):45-50. doi: 10.1126/science. 1234379 .

Bateman, Ian J., Georgina M. Mace, Carlo Fezzi, Giles Atkinson, and Kerry Turner. 2011. "Economic Analysis for Ecosystem Service Assessments." Environmental \& Resource Economics no. 48 (2):177-218. doi: 10.1007/s10640-010-9418-x. 
Bullock, J. M., J. Aronson, A. C. Newton, R. F. Pywell, and J. M. Rey-Benayas. 2011. "Restoration of ecosystem services and biodiversity: conflicts and opportunities." Trends in Ecology \& Evolution no. 26 (10):541-549. doi: 10.1016/j.tree.2011.06.011.

Cardinale, Bradley J., J. Emmett Duffy, Andrew Gonzalez, David U. Hooper, Charles Perrings, Patrick Venail, Anita Narwani, Georgina M. Mace, David Tilman, David A. Wardle, Ann P. Kinzig, Gretchen C. Daily, Michel Loreau, James B. Grace, Anne Larigauderie, Diane S. Srivastava, and Shahid Naeem. 2012. "Biodiversity loss and its impact on humanity." Nature no. 486 (7401):59-67. doi: 10.1038/nature11148.

De Groot, Rudolf S., James Blignaut, Sander Van Der Ploeg, James Aronson, Thomas Elmqvist, and Joshua Farley. 2013. "Benefits of Investing in Ecosystem Restoration." Conservation Biology no. 27 (6):1286-1293. doi: 10.1111/cobi.12158.

De Groot, Rudolf, Johan Van der Perk, Anna Chiesura, and Arnold van Vliet. 2003. "Importance and threat as determining factors for criticality of natural capital." Ecological Economics no. 44 (2-3):187-204. doi: http://dx.doi.org/10.1016/S0921-8009(02)00273-2.

DeFries, Ruth, and Harini Nagendra. 2017. "Ecosystem management as a wicked problem." Science no. 356 (6335):265-270. doi: 10.1126/science.aal1950.

Edens, B., and L. Hein. 2013. "Towards a consistent approach for ecosystem accounting." Ecological Economics no. 90:41-52. doi: 10.1016/j.ecolecon.2013.03.003.

Fisher, B, and R.K. Turner. 2008. "Ecosystem services: classification for valuation " Biological Conservation. no. 141:1167-1169.

Fisher, B., K. Turner, M. Zylstra, R. Brouwer, R. de Groot, S. Farber, P. Ferraro, R. Green, D. Hadley, J. Harlow, P. Jefferiss, C. Kirkby, P. Morling, S. Mowatt, R. Naidoo, J. Paavola, B. Strassburg, D. Yu, and A. Balmford. 2008. "Ecosystem services and economic theory: integration for policy-relevant research " Ecological Applications no. 18 (8):2050-2067.

Hein, Lars, Ken Bagstad, Bram Edens, Carl Obst, Rixt de Jong, and Jan Peter Lesschen. 2016. "Defining ecosystem assets for natural capital accounting." PLOS ONE no. 11 (11):e0164460. doi: 10.1371/journal.pone.0164460.

Mace, G. M. 2014. "Whose conservation?" Science no. 345 (6204):1558-1560. doi: $10.1126 /$ science. 1254704 .

Mace, Georgina M., Rosemary S. Hails, Philip Cryle, Julian Harlow, and Stewart J. Clarke. 2015. "Towards a risk register for natural capital." Journal of Applied Ecology no. 52 (3):641-653. doi: 10.1111/1365-2664.12431.

Mace, Georgina M., Ken Norris, and Alastair H. Fitter. 2012. "Biodiversity and ecosystem services: a multilayered relationship." Trends in Ecology \& Evolution no. 27 (1):19-26.

Manning, Peter, Fons van der Plas, Santiago Soliveres, Eric Allan, Fernando T. Maestre, Georgina Mace, Mark J. Whittingham, and Markus Fischer. 2018. "Redefining ecosystem multifunctionality." Nature Ecology \& Evolution no. 2 (3):427-436. doi: 10.1038/s41559017-0461-7.

Millennium Ecosystem Assessment. 2005. Ecosystems and Human Well-being: Synthesis. Washington DC: World Resources Institute.

Natural Capital Committee. 2013. The state of natural capital: towards a framework for measurement and valuation. London: Natural Capital Committee.

Natural Capital Committee. 2014. State of Natural Capital: restoring our natural assets. London: Natural Capital Committee.

Natural Capital Committee. 2015. The state of natural capital: protecting and improving natural capital for prosperity and wellbeing. London: Natural Capital Committee. 
Nelson, E., G. Mendoza, J. Regetz, S. Polasky, H. Tallis, D. R. Cameron, K. M. A. Chan, G. C. Daily, J. Goldstein, P. M. Kareiva, E. Lonsdorf, R. Naidoo, T. H. Ricketts, and M. R. Shaw. 2009. "Modeling multiple ecosystem services, biodiversity conservation, commodity production, and tradeoffs at landscape scales." Frontiers in Ecology and the Environment no. 7 (1):4-11. doi: $10.1890 / 080023$.

Oliver, Tom H., Matthew S. Heard, Nick J. B. Isaac, David B. Roy, Deborah Procter, Felix Eigenbrod, Rob Freckleton, Andy Hector, C. David L. Orme, Owen L. Petchey, Vânia Proença, David Raffaelli, K. Blake Suttle, Georgina M. Mace, Berta Martín-López, Ben A. Woodcock, and James M. Bullock. 2015. "Biodiversity and Resilience of Ecosystem Functions." Trends in Ecology \& Evolution no. 30 (11):673-684. doi: http://dx.doi.org/10.1016/j.tree.2015.08.009.

Ouyang, Zhiyun, Hua Zheng, Yi Xiao, Stephen Polasky, Jianguo Liu, Weihua Xu, Qiao Wang, Lu Zhang, Yang Xiao, Enming Rao, Ling Jiang, Fei Lu, Xiaoke Wang, Guangbin Yang, Shihan Gong, Bingfang Wu, Yuan Zeng, Wu Yang, and Gretchen C. Daily. 2016. "Improvements in ecosystem services from investments in natural capital." Science no. 352 (6292):1455-1459. doi: 10.1126/science.aaf2295.

Pearson, Richard G. 2016. "Reasons to Conserve Nature." Trends in Ecology \& Evolution no. 31 (5):366-371. doi: http://dx.doi.org/10.1016/j.tree.2016.02.005.

Raudsepp-Hearne, C., G. D. Peterson, and E. M. Bennett. 2010. "Ecosystem service bundles for analyzing tradeoffs in diverse landscapes." Proceedings of the National Academy of Sciences no. 107 (11):5242-5247. doi: 10.1073/pnas.0907284107.

Rockstrom, J., W. Steffen, K. Noone, A. Persson, F. S. Chapin, E. F. Lambin, T. M. Lenton, M. Scheffer, C. Folke, H. J. Schellnhuber, B. Nykvist, C. A. de Wit, T. Hughes, S. van der Leeuw, H. Rodhe, S. Sorlin, P. K. Snyder, R. Costanza, U. Svedin, M. Falkenmark, L. Karlberg, R. W. Corell, V. J. Fabry, J. Hansen, B. Walker, D. Liverman, K. Richardson, P. Crutzen, and J. A. Foley. 2009. "A safe operating space for humanity." Nature no. 461 (7263):472-475. doi: 10.1038/461472a.

Sen, A. 2010. "Equality of What?" The Tanner lectures on human values no. 4:195-220.

Silvertown, Jonathan. 2015. "Have Ecosystem Services Been Oversold?" Trends in Ecology \& Evolution no. 30 (11):641-648.

Steffen, Will, Katherine Richardson, Johan Rockström, Sarah E. Cornell, Ingo Fetzer, Elena M. Bennett, Reinette Biggs, Stephen R. Carpenter, Wim de Vries, Cynthia A. de Wit, Carl Folke, Dieter Gerten, Jens Heinke, Georgina M. Mace, Linn M. Persson, Veerabhadran Ramanathan, Belinda Reyers, and Sverker Sörlin. 2015. "Planetary boundaries: Guiding human development on a changing planet." Science no. 347 (6223). doi: 10.1126/science.1259855. 